\title{
Amyotrophic Lateral Sclerosis and Language Dysfunction: Kana, Kanji and a Prescient Report in Japanese by Watanabe (1893)
}

\author{
Hiroo Ichikawa ${ }^{a}$ Michael W. Miller ${ }^{b}$ Mitsuru Kawamura ${ }^{a}$ \\ a Department of Neurology, Showa University School of Medicine, and ${ }^{\mathrm{b}}$ Medical Sciences Training Programme, \\ Faculty of Medicine, University of Tokyo, Tokyo, Japan
}

\section{Key Words}

Amyotrophic lateral sclerosis - Motor neuron disease •

Frontotemporal lobar degeneration · Aphasia

\begin{abstract}
Although Charcot described amyotrophic lateral sclerosis (ALS) in the 1870s, he did not focus on language. And language problems in ALS with or without dementia were long ignored. A recent report by Caselli et al. [Ann Neurol 1993;33: 200-207] is accurately regarded as a major breakthrough in studies of language in ALS. However, we discovered a Japanese account written by Watanabe in 1893 describing paragraphia of an aphasic nature, and this is interesting for two reasons. (1) Watanabe's paper is, we believe, the first report of an aphasia associated with motor neuron disease, and predates other reports by 100 years. (2) It sheds light on the dissociated involvement of the two Japanese writing systems: kana (Japanese simple phonograms) and kanji (Japanese morphograms with complex character derived from Chinese characters). In the aphasia reported by Watanabe, the phonograms are more affected than the morphograms. Thus, Watanabe's clinical observation may predict current theories of the way in which these two writing systems involve different intrahemispheric pathways.
\end{abstract}

Copyright $\odot 2011$ S. Karger AG, Basel

\section{Introduction}

Definition of la sclérose amyotrophique (amyotrophic lateral sclerosis, ALS) by Jean-Martin Charcot (18251893) and colleagues in the 1870s [1-6] made a significant contribution to clinical understanding of the disease and to understanding of the pyramidal tract, but did not consider the cognitive domain [1-3]. For a long time, ALS was thought to selectively involve the motor neuron system, and was viewed solely as motor neuron disease (MND) [2]. Although cognitive and behavioral problems in ALS and/or MND (ALS/MND) were described in both European and Japanese literature, with pathological evidence showing extra-motor involvement [4-11], these conclusions were not widely accepted until the late 1900s [9-13]. Furthermore, language dysfunction attracted less interest [9-13] until the report on aphasic dementia with MND by Caselli et al. [14], despite earlier description of pure agraphia by Ferguson and Boller [15].

The importance of these findings was reestablished in light of a connection between frontotemporal lobar degeneration (FTLD) $[16,17]$ and immunopathological evidence, including discovery of transactivation response DNA-binding protein with a molecular weight of $43 \mathrm{kDa}$ (TDP-43) [18-20]. The typical clinical feature of FTLD in $\mathrm{MND} / \mathrm{ALS}$ is now recognized as frontotemporal demen-

\section{KARGER}

Fax +4161306 1234 E-Mail karger@karger.ch www.karger.com
(C) 2011 S. Karger AG, Basel 0014-3022/11/0653-0144\$38.00/0

Accessible online at:

www.karger.com/ene
Hiroo Ichikawa, MD

Department of Neurology, Showa University School of Medicine

1-5-8 Hatanodai, Shinagawa-ku

Tokyo 142-8666 (Japan)

Tel. +81 33784 8781, E-Mail h_ichikawa0527@yahoo.co.jp 
Fig. 1. A picture of the Okayama Medical Association established in 1889 (a) and a book cover of the journal of the Association at that time (b). From http://www. journalarchive.jst.go.jp/english/jnlabstracten.php?cdjournal=joma1889\&cdvol $=5 \&$ noissue $=40 \&$ startpage $=138$.
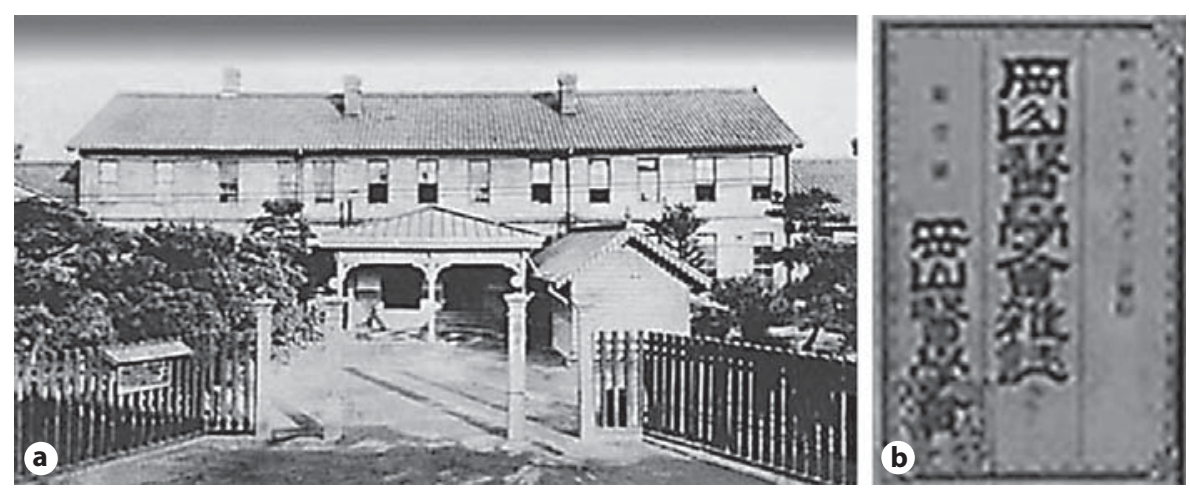

tia (FTD) manifesting itself in behavioral disorder [16, 17]. Furthermore, language disorders in FTLD are thought to include progressive non-fluent aphasia and semantic dementia $[16,17]$. Reports on language impairment in MND/ALS have steadily accumulated [21-33] after description of aphasic dementia with MND by Caselli et al. [14].

In addition to the report by Ferguson and Boller (1977) [15], there is also a prescient Japanese, clinical report by Watanabe [34] that addresses language function: 'A patient who manifested cortical motor aphasia concurrently with bulbar and progressive muscular atrophy' [34] published in 1893 in the Journal of the Okayama Medical Association (fig. 1). It comes only 20 years after the first account of ALS by Charcot, but extends his seminal work by addressing language dysfunction.

\section{A Translation of Watanabe's Report}

In this translation, comments in square brackets are the translator's. Those in round brackets are remarks by Watanabe.

Title: 'A patient who manifested cortical motor aphasia concurrently with bulbar and progressive muscular atrophy'. Eikichi Watanabe (1893).

The patient is a 41-year-old man who lives in Nakasyo village, Utsu County, in Okayama prefecture and does odd jobs. His parents are in good health, but his grandfather died of a stroke. He has four siblings: one died of dysentery and the remaining 3 are in good health. The patient was in good health in childhood, except for febrile disease at the age of one and measles at age 10 . He underwent vaccination three times. He sometimes visited our main hospital due to toothache, but had no other diseases including syphilis. His speech was halting from last
April, and he was able to say little by October. From last November, he became unable to use chopsticks with his right hand and had to use a spoon to eat. He then had difficulty swallowing and took time to eat. At around this time, his writing became incomprehensible, and he was unable to blow and light charcoal without pinching his nose [charcoal was used for heating and cooking in this period]. He visited our hospital due to gradually worsening symptoms. (These descriptions are based on his mother's documentation of May 9th.) His musculature was moderate, but he was thin and malnourished. His arterial pulse was light, his appetite moderate, and his bowel movements were normal. Examination of his chest and abdomen revealed nothing significant. Urinalysis was normal. The patient was always smiling. His mouth was always open, his upper lip retracted, and his lower lip loose. He could close his mouth and suck in his cheeks, but could not pucker his mouth and whistle with contracted lips. He could open and close his eyes, and eye movement was intact. His tongue was atrophic and small with an irregular surface, withdrawn to the bottom of his mouth. The right anterior tongue was more severely atrophic than the left. He could move his tongue back, but could not extend it beyond his teeth. He could not blow out a candle without pinching his nose. He blew cigarette smoke from both mouth and nose, suggesting incomplete movement of the soft palate. When asked to pronounce sounds, all were undistinguishable except for vowel sounds. Sounds that required movements of the lips, tongue, and oropharygeal muscles were difficult to understand. His swallowing was severely impaired, and he was unable to swallow saliva, so he always had to wipe it away with a towel. Reactions of nerves and muscles to moderate electrical stimulation were severely diminished or absent. Atrophy was observed in thenar and dorsal interosseous muscles with right-side dominancy. Grip was 
Fig. 2. Part of Watanabe's original report (1893). a The translation of the Japanese title (left to right) is: 'A patient who manifested cortical motor aphasia concurrently with bulbar and progressive muscular atrophy'. b The author's name written in kanji reads Eikichi Watanabe. c-j Other descriptions are partial quotations from the text of the paper written in a mixture of (kata-) kana and kanji. Relatively complex characters are kanji and simpler letters are kana. For a detailed explanation of the text in $\mathbf{c}-\mathbf{j}$, see translation in the text. Note that the Japanese text reads right to left in $\mathbf{a}-\mathbf{j}$, and top to bottom, as may also be the case.

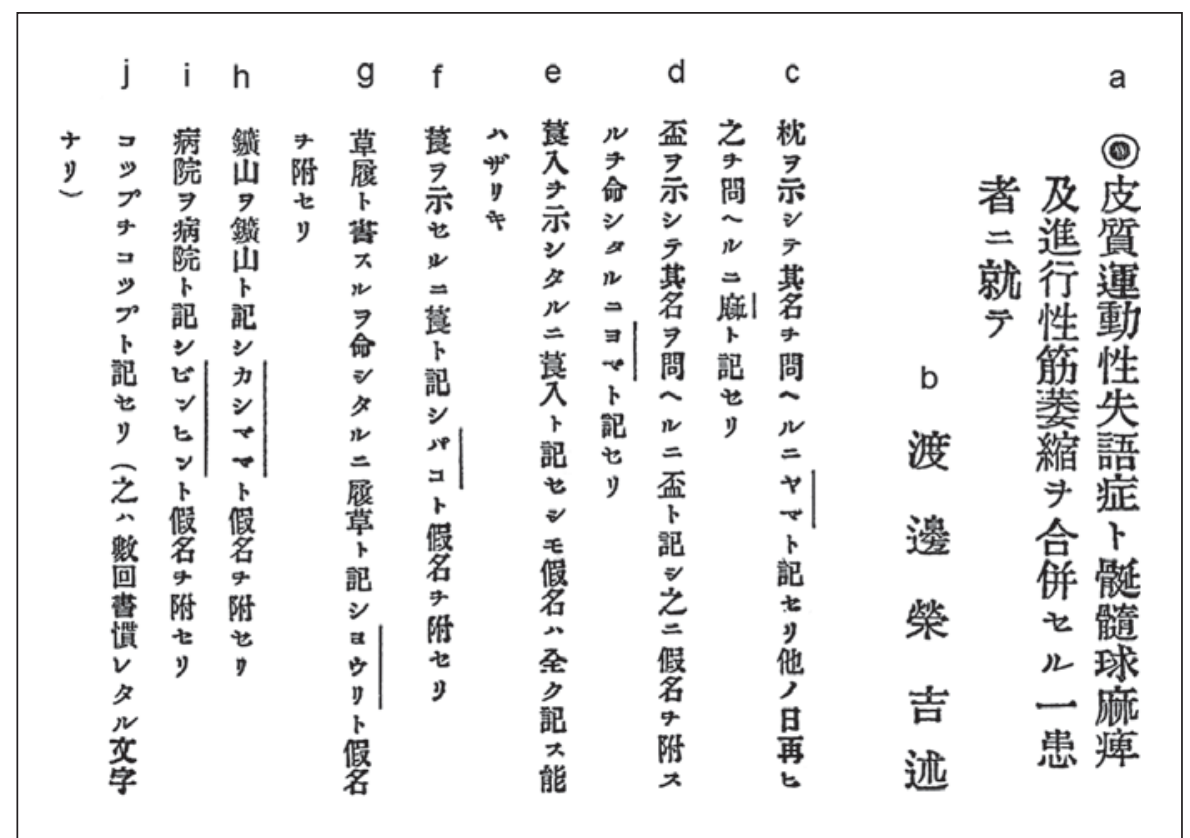

severely diminished, with measurements of 6 and $5 \mathrm{~kg}$ for the right and left hands, respectively. The lengths of the right and left forearms were 10.5 and $11.5 \mathrm{~cm}$, respectively, and those of the right and left upper arms were 11.5 and $12.5 \mathrm{~cm}$, respectively. His shoulder tips were pronounced. Atrophy was also observed in other muscles, including upper limbs, arms, and scapula muscles. He was unable to use chopsticks, as already described, but he could use a writing [calligraphy] brush. The lower limbs were well preserved with normal reflexes. Sensory deficits were not observed (although an exact examination was difficult). These observations indicated bulbar palsy and progressive muscular atrophy, with initial development of bulbar palsy followed by progressive muscular atrophy.

The patient was unable to speak and made many writing errors when instructed to write answers to questions. Kana mistakes predominated. When mistakes were pointed out, he tried to correct them. Finally, he would choose correct [written] characters or fail to write. Errors in kanji included mistakes with the same pronunciation, but different meanings (e.g. 熱シ [atsu-shi], meaning hot $\rightarrow$ 厚四 [atsu-shi], meaning thick and four), plus errors with similarity in only the first sound (e.g. 枕 [makura], meaning pillow $\rightarrow$ 麻 [ma], meaning hemp), and completely different characters without similarity. Writing of familiar characters was relatively preserved (e.g. writing an ordered list of kana syllables).
The following are the mistakes he made when asked to write down characters pointed out to him. For 枕 [makura], meaning pillow, he wrote ヤマ [ya ma] in kana (fig. 2c), and on another day wrote 麻 [ma], meaning hemp. For 盃 [sakazuki], meaning Japanese sake cup, he wrote 盃 in kanji correctly, but $\exists マ$ [yo ma] (no meaning) in kana (fig. 2d). For 莨入 [tabaco ire], meaning cigarette pouch, he wrote 莨入 in kanji correctly, but failed to write the word in kana (fig. 2e). For 莨 [tabaco], meaning cigarette, he wrote 莨 in kanji correctly, but バコ [ba ko] (no meaning) in kana [note: 夕 [ta] is omitted from タバコ] (fig. 2f). These writing errors show predominant involvement of kana.

When touching his skin with a cold object and asked whether it was cold or hot, he wrote 水 [koori], meaning ice, in kanji, but wrote ツツシ [ttsu shi] (no meaning) in kana. When touching his skin with a hot object, he wrote 厚于 [atsu chi], paragraphia of the same sounds but with a different meaning: 'thick' in kanji. When electrostimulating his skin, he wrote 慮 [ryo], meaning 'captive' [Watanabe interpreted this as 'horrible feeling']. These were examples. It should be mentioned that he had received an excellent education in writing kanji. [There was no statutory schooling of children at this time, so we can only guess that he was taught by a family member, or perhaps at a local Buddhist temple.]

In dictation, he also made many mistakes or could not write. For 草履 [zou ri], meaning Japanese straw sandals, 
he wrote 履草 [ri zou] in kanji, but back to front [in the original Japanese script this runs top to bottom of the page], and ヨウリ [yo u ri] (no meaning) in kana [note: $\exists$ is a substitution for ゾ [zo] (fig. 2g)]. For 鐄山 [kou zan], meaning mine [like a coal mine, for example], he wrote 鑛山 in kanji correctly, but カシママ [ka shi ma ma] (no meaning) in kana (fig. 2h). For 病院 [byou in], meaning hospital, he wrote 病院 in kanji correctly, but ビンヒン [bi n hi n] (no meaning) in kana (fig. 2i). For コップ [coppu] [meaning cup], he wrote コップ correctly (he was familiar with this word) (fig. 2j). Thus, writing errors mainly involved kana. On the other hand, he could copy characters without mistakes and understand the meaning of written characters well. In fact, he always had a few storybooks with him. When shown written instructions, he could respond correctly to what was read: 'raise your hands up', 'grip your hands', 'close your eyes', 'tie your laces [of clothes]', and 'take your medicine'. However, he was unable to read aloud. He understood instructions, but gestured his agreement or disagreement. However, he could not repeat words. He sometimes could not identify the number of written syllables. We do not observe such signs in typical bulbar palsy patients (it is possible this observation comes from contemporary literature rather than personal observation).

The following is a summary of the patient. He was unable to speak on his own. He was unable to write or made many mistakes in dictation (paragraphia). He was unable to speak out to imitate what others said. He sometimes could not identify the number of written syllables. He was unable to read aloud. However, he understood well what others said. He also understood written characters and was able to copy them.

Thus, we think that the patient had so-called incomplete transcortical motor aphasia. In addition, psychiatric changes were noticeable: the patient was always smiling and good-tempered without abnormal behavior. In the middle of April, he became irritable. When he was instructed to visit the electrical stimulation room, he was not easily convinced and resisted by turning his head. He even broke things, and that made him feel uncomfortable. These symptoms did not respond to medical treatment, and therefore the patient appeared not to have a true psychiatric disorder.

Transcortical motor aphasia observed in this patient is known to be caused by damage in the posterior third of the left inferior frontal gyrus, which is connected by pyramidal tract fibers with the region responsible for bulbar palsy. Thus, progressive degeneration along the pyramidal tract may often produce the condition ob- served in the current patient (similarly, patients with damage in the primary motor cortex develop degeneration along the pyramidal tract). It remains unproven whether aphasia develops subsequent to bulbar palsy [end of translation].

\section{Discussion}

In the late 19th century, Japan produced 2 pioneers in the neurological field [35]. The first, Hiroshi Kawahara (1858-1918), reported the first, two-brother cases of bulbar and spinal muscular atrophy of X-linked recession [35]. The second, Kinnosuke Miura (1864-1950), who worked in Charcot's Laboratory at Salpêtrière Hospital, published a clinical and pathological study of ALS [35]. So this period in Japan produced important work on ALS/MND. We do not know if Watanabe had links with these two early researchers, but his report is valuable, nevertheless, for anticipating our current understanding of ALS/MND as a cognitive disorder. Although clinicopathological findings suggestive of these connections are also found in early descriptions of ALS/MND patients [4-8], observation of language problems is relatively new [9-13]. And to the best of our knowledge, Ferguson and Boller give the first modern report [15]. In 1893, however, Watanabe [34] described language impairment in an MND patient long before any firm knowledge of a connection between ALS/MND and cognitive disorder. His report is also the first on aphasia in Japan (fig. 3) [12, 13]. Japanese case studies of aphasia thus began with an MND patient.

Watanabe's patient developed writing problems several months after onset of motor symptoms, beginning with bulbar palsy. Paragraphia was established about a year after he became unable to speak. Although Watanabe interpreted the features of paragraphia as incomplete transcortical motor aphasia, there is some doubt about this diagnosis when spoken language is not available. However, this may explain why language problems have been missed in ALS/MND, because patients develop dysarthria due to ALS/MND, especially with bulbar symptoms. In support of this argument, in the ALS language breakthrough report by Caselli et al. [14], there is a description of speech so impaired that patients were incomprehensible: the aphasic nature of their disturbance only became evident when written language was assessed. It is possible that speech disturbance was attributed to dysarthria, and fundamental language problems were overlooked in ALS/MND [16, 17]. 


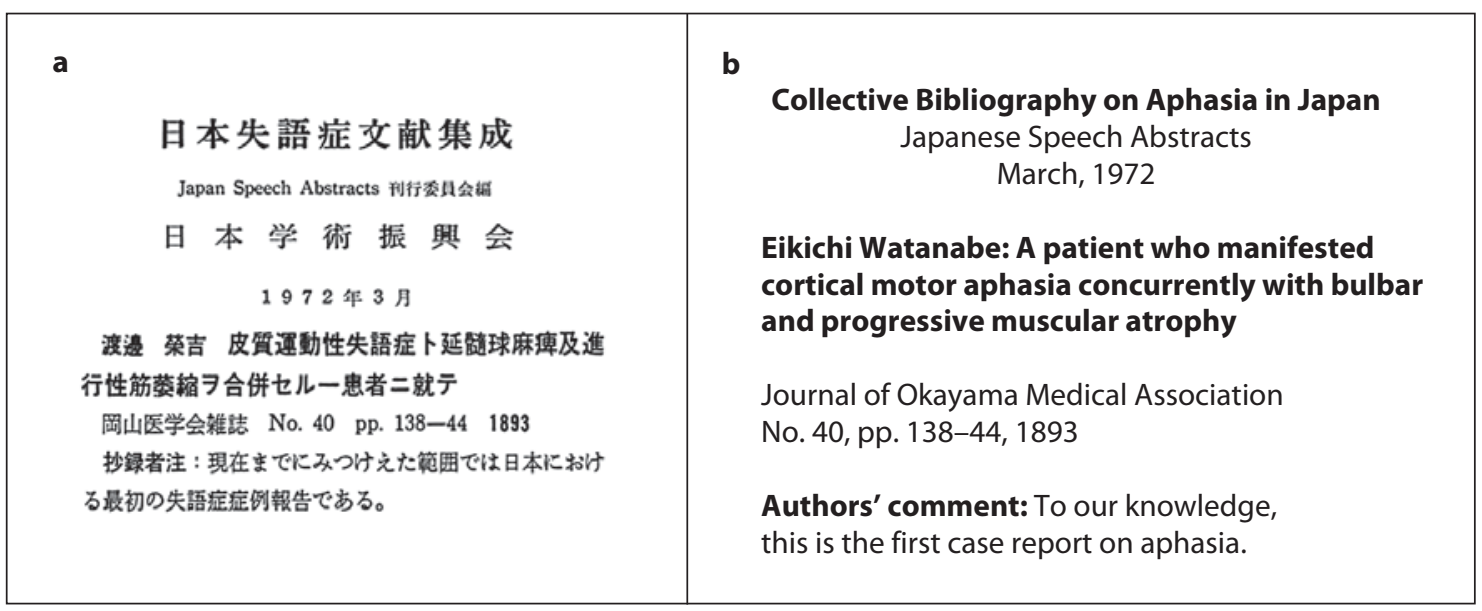

Fig. 3. Text from the Collective Bibliography on Aphasia in Japan, showing the report is the first on aphasia. a Original Japanese description. b Translation.

Watanabe [34] also described dissociated involvement of the two Japanese writing systems (kana: simplified phonograms with strict pronunciation for each character, and relatively easy to write, and kanji: morphograms derived from the Chinese, sometimes of ambiguous pronunciation and difficult to write) with preferential impairment of kana writing. Watanabe's study first came to our attention when we reported that kana errors are usually more common than kanji in ALS, especially bulbaronset patients [29, 30]. Modern Japanese schoolchildren require 9 years to learn kanji, and a complex character written by hand may involve up to seventeen separate strokes, but they take only 3 years to learn kana. More recently, we found a possible dissociation between kana and kanji in ALS patients, in association with brain atrophy topography [31]. Furthermore, kana errors are significantly associated with enlargement of the anterior horns of the lateral ventricles, suggesting frontal atrophy, while kanji errors are significantly associated with enlargement of the inferior horns of the lateral ventricles, suggesting temporal atrophy [31]. Such dissociation linked with the dual writing system has been exclusively studied in patients with cerebrovascular diseases [35-41]. Watanabe's report also suggests that 'paragraphia' is associated with differential damage to control of the two writing systems, and not simply attributable to brain anoxia due to respiratory failure, physical disability and attention deficits. Moreover, in Watanabe's report [34], there is a description of impaired letter-number use, suggesting impaired 'mora' comprehension, as recently reported in a patient with ALS/MND with omission of kana letters [26, 32]. Watanabe [34] also reported that his patient was always smiling, and this indicates lack of illness awareness and suggests his patient had MND with dementia, also known as Yuasa-Mitsuyama type MND in Japan $[7,8,12,13]$. We have also indicated the importance of lack of illness awareness in ALS patients with dementia [29]. Watanabe's prescient report [34] is thus not only historically interesting, but points towards current understanding of language disturbance in ALS/MND.

\section{Acknowledgements}

This report was supported by Showa University Medical Foundation; a grant from the Tamagawa University Center of Excellence under the Ministry of Education, Culture, Sports, Science and Technology (MEXT); Core Research for Evolutionary Science and Technology (CREST No. 17022035), KAKENHI (No. 2100295); a Grant-in-Aid for Scientific Research on Priority Areas - System Study on High-Order Brain Functions from Showa University Grant-in-Aid for Innovative Collaborative Research Projects, and a Special Research Grant-in-Aid for Development of Characteristic Education from MEXT.

\section{Disclosure Statement}

None of the authors has a conflict of interest regarding the work presented in the manuscript. The study was conducted with institutional support only. 


\section{References}

1 Charcot J-M: Amyotrophies spinales deuteropathiques sclérose latérale amyotrophique \& sclérose latérale amyotrophique. Bureaux du Progrès Médical 1874;2:234-266.

2 Brain WR: Diseases of the Nervous System. Oxford, Oxford University Press, 1962, pp 531-534.

3 Goetz CG, Bonduelle M, Gelfand T: Charcot. Constructing Neurology. New York, Oxford University Press, 1995.

-4 Meyer A: Über eine der amyotrophischen Lateralsklerose nahestehende Erkrankung mit psychiatrischen Störungen. Z Ges Neurol Psychiatr 1929;121:107-138.

5 Ziegler LH: Psychotic and emotional phenomenoa associated with ALS. Arch Neurol Psychiatry 1930;24:930-936.

-6 Castaigne P, Lhermitte F, Cambier J, Escourolle R, Le Bigot P: Etude neuropathologique de 61 observations de sclerose laterale amyotrophique. Rev Neurol 1972;127:401-414.

7 Yuasa R: Amyotrophic lateral sclerosis with dementia. Clin Neurol (Tokyo) 1970;10:569577.

-8 Mitsuyama Y, Takamiya S: Presenile dementia with motor neuron disease. Arch Neurol 1979;36:592-593.

-9 Bak TH, Hodges JR: Cognition, language and behavior in motor neuron disease: evidence of frontotemporal dysfunction. Dement Geriatr Cogn Disord 1999;10(suppl 1):29-32.

-10 Bak TH, Hodges JR: Motor neuron disease, dementia and aphasia: coincidence, co-occurrence or continuum? J Neurol 2001;274: 260-270.

11 Bak TH, Hodges HR: The effects of motor neuron disease on language: further evidence. Brain Lang 2004;89:354-361.

- 12 Kawamura M, Ichikawa H, Koyama S, Ishihara K: Amyotrophic lateral sclerosis with dementia: neuropsychological aspects. Brain Nerve (Tokyo) 2007;59:1083-1091.

13 Ichikawa H, Kawamura M: Language impairment in amyotrophic lateral sclerosis. Brain Nerve (Tokyo) 2010;62:435-440.

14 Caselli RJ, Windebank AJ, Petersen RC, Komori T, Parisi JE, Okazaki H, Kokmen E, Iverson R, Dinapoli RP, Graff-Radford NR, et al: Rapidly progressive aphasic dementia and motor neuron disease. Ann Neurol 1993; 33:200-207.

$\checkmark 15$ Ferguson JH, Boller F: A different form of agraphia: syntactic writing errors in patients with motor speech and movement disorders. Brain Lang 1977;4:382-389.

16 Snowden JS, Neary D, Mann DMA: Frontotemporal lobar degeneration: fronto-temporal dementia. Progressive aphasia, semantic dementia. Clinical Neurology and Neurosurgery Monographs. New York, Churchill Livingstone, 1996.
17 Neary D, Snowden JS, Gustafson L, Passant U, Stuss D, Black S, Freedman M, Kertesz A, Robert PH, Albert M, Boone K, Miller BL, Cummings J, Benson DF: Frontotemporal lobar degeneration: a consensus on clinical diagnostic criteria. Neurology 1998;51: 1546-1554.

18 Okamoto K: Ubiquitin-positive tau-negative intraneuronal inclusions in dementia with motor neuron disease. Neuropathology DOI: $10.1111 / j .1440-1789.2010 .01121 . x$

19 Neumann M, Sampathu DM, Kwong LK, Truax AC, Micsenyi MC, Chou TT, Bruce J, Schuck T, Grossman M, Clark CM, McCluskey LF, Miller BL, Masliah E, Mackenzie IR, Feldman H, Feiden W, Kretzschmar HA, Trojanowski JQ, Lee VM: Ubiquitinated TDP-43 in frontotemporal lobar degeneration and amyotrophic lateral sclerosis. Science 2006;314:130-133.

20 Geser F, Lee VM-Y, Trojanowski JQ: Amyotrophic lateral sclerosis and frontotemporal degeneration: a spectrum of TDP-43 proteinopathies. Neuropathology 201;30:103112.

21 Rakowicz W, Hodges JR: Dementia and aphasia in motor neuron disease: an underrecognized association? J Neurol Neurosurg Psychiatry 1998;65:881-889.

22 Tsuchiya K, Ozawa E, Fukushima J, Yasui H, Kondo H, Nakano I, Ikeda K: Rapidly progressive aphasia and motor neuron disease: clinical, radiological, and pathological study of an autopsy case with circumscribed lobar atrophy. Acta Neuropathol (Berl) 2000;99: 81-87.

23 Bak TH, O'Donovan DG, Xuereb JH, Boniface S, Hodges JR: Selective impairment of verb processing associated with pathological changes in Brodmann areas 44 and 45 in the motor neuron disease-dementia-aphasia syndrome. Brain 2001;124:103-120.

24 Catani M, Piccirilli M, Geloso MC, Cherubini A, Finali G, Pelliccioli G, Senin U, Mecocci P: Rapidly progressive aphasic dementia with motor neuron disease: a distinctive clinical entity. Dement Geriatr Cogn Disord 2004; 17:21-28.

25 Iroi A, Okuma Y, Fukae J, Fujishima K, Goto K, Mizuno Y: Amyotrophic lateral sclerosis presented with alexia of kanji and word meaning aphasia. Brain Nerve (Tokyo) 2002 54:903-907.

26 Kanzaki M, Sato M, Ogawa G, Miyamoto N, Motoyoshi K, Kamakura K, Takeda K: A case of dementia with motor neuron disease associated agraphia: the omission of kana letters. Clin Neurol (Tokyo) 2004;44:673-676.

27 da Rosha AJ, Valerio BCO, Buainain RP, Ferraz ME, da Silva CJ, Maria ACM Jr, Andrade VP, Lancelloti CLP: Motor neuron disease associated with non-fluent rapidly progressive aphasia: case report and review of the literature. Eur J Neurol 2007;14:971-975.
28 Kim SH, Seo AW, Go SM, Suh MK, Chin J: Semantic dementia combined with motor neuron disease. J Clin Neurosci 2009;16: 1683-1685.

29 Ichikawa H, Koyama S, Ohno H, Ishihara K, Nagumo K, Kawamura M: Writing errors and anosognosia in amyotrophic lateral sclerosis with dementia. Behav Neurol 2008;19: 107-116.

30 Ichikawa H, Takahashi N, Hieda S, Ohno H, Kawamura M: Agraphia in bulbar-onset amyotrophic lateral sclerosis: not merely a consequence of dementia or aphasia. Behav Neurol 2008;20:91-99.

- 31 Ichikawa H, Hieda S, Ohno H, Ohnaka Y, Shimizu Y, Nakajima M, Kawamura M: Kana versus kanji in amyotrophic lateral sclerosis: a clinicoradiological study of writing errors. Eur Neurol 2010;64:148-155.

-32 Tsuji-Akimoto S, Hamada S, Yabe I, Tamura I, Otsuki M, Kobayashi S, Sasaki H: Writing errors as a result of frontal dysfunction in Japanese patients with amyotrophic lateral sclerosis. J Neurol Epub 2010;257:2071-2077.

- 33 Ishihara K, Ichikawa H, Suzuki Y, Shiota J, Nakano I, Kawamura M: Is a lesion of Exner's area responsible for progressive agraphia in amyotrophic lateral sclerosis with dementia? An autopsy case report. Behav Neurol 2010; 23:153-158.

34 Watanabe E: [no English title]. J Okayama Med Assoc 1893;5:138-144. http://www. journalarchive.jst.go.jp/english/jnlabstract_ en.php?cdjournal=joma $1889 \& \mathrm{cdvol}=5 \&$ noissue $=40 \&$ startpage $=138$.

35 Takahashi A: The growing-up and background of clinical neurology in Japan. Clin Neurol 2002;42:1044-1053.

36 Iwata M: Neural mechanism of reading and writing in the Japanese language. Funct Neurol 1986;1:43-52.

-37 Kawamura M, Hirayama K, Hasegawa K, Takahashi N, Yamaura M: Alexia with agraphia of kanji (Japanese morphograms). J Neurol Neurosci 1987;50:1125-1129.

- 38 Kawamura M, Hirayama K, Yamamoto H: Different interhemispheric transfer of kanji and kana writing evidenced by a case with left unilateral agraphia without apraxia. Brain 1989;112:1011-1018.

39 Soma Y, Yamadori A, Murata S, Imanaga H: Lexical agraphia in the Japanese language. Brain 1989;112:1549-1561.

40 Yokota T, Ishiai S, Furukawa T, Tsukagoshi $\mathrm{H}$ : Pure agraphia of kanji due to thrombosis of the Labbe vein. J Neurol Neurosurg Psychiatry 1990;53:335-338

41 Sakurai Y, Matsumura K, Iwatsubo T, Momose T: Frontal pure agraphia for kanji or kana: dissociation between morphology and phonology. Neurology 1997;49:946-952. 